\title{
Drivers of taxonomic bias in conservation research : a global analysis of terrestrial mammals
}

dos Santos, J. W.

2020-12-12

dos Santos , J W , Correia , R A , Malhado , A C M , Campos-Silva , J , Teles , D , Jepson , $P$ \& Ladle , R J 2020 , ' Drivers of taxonomic bias in conservation research : a global analysis of terrestrial mammals ' , Animal Conservation , vol. 23 , no. 6 , pp. 679-688 . https://doi.org/10.1111/acv.12

http://hdl.handle.net/10138/322854

https://doi.org/10.1111/acv.12586

acceptedVersion

Downloaded from Helda, University of Helsinki institutional repository.

This is an electronic reprint of the original article.

This reprint may differ from the original in pagination and typographic detail.

Please cite the original version. 
4 Authors: Janisson W. dos Santos ${ }^{1 *}$, Ricardo A. Correia ${ }^{1,2,3}$, Ana C. M. Malhado ${ }^{1}$, João V. 5 Campos-Silva ${ }^{1,4}$, Davi Teles ${ }^{1}$, Paul Jepson ${ }^{5}$, Richard J. Ladle ${ }^{1}$

6

$7{ }^{1}$ Institute of Biological Science and Health, Federal University of Alagoas, Campus A. C.

8 Simões, Maceió, Alagoas, Brazil.

$9 \quad{ }^{2}$ Helsinki Lab of Interdisciplinary Conservation Science, Department of Geosciences and 10 Geography, University of Helsinki, Finland.

$11{ }^{3}$ Helsinki Institute for Sustainability Science, University of Helsinki, Finland.

$12{ }^{4}$ Faculty of Environmental Sciences and Natural Resource Management, Norwegian.

13 University of Life Sciences, Ås, Norway.

$14 \quad{ }^{5}$ Ecosulis, Paul Street, London, England.

15

16 *Corresponding author: janisson.santos@icbs.ufal.br 


\section{Abstract}

19 Scientific knowledge of species and the ecosystems they inhabit is the cornerstone of modern

20 conservation. However, research effort is not spread evenly among taxa (taxonomic bias), which may constrain capacity to identify conservation risk and to implement effective responses. Addressing such biases requires an understanding of factors that promote or constrain the use of a particular species in research projects. To this end, we quantified conservation science knowledge of the world's extant non-marine mammal species $(n=4,108)$ based on the number of published documents in journals indexed on Clarivate Analytics' Web of Science ${ }^{\mathrm{TM}}$. We use an innovative hurdle model approach to assess the relative importance of several ecological, biogeographical and cultural factors for explaining variation in research production between species. The most important variable explaining the presence/absence of conservation research was scientific capacity of countries within the range of the species, followed by body mass and years since the taxonomic description. Research volume (more than one document) was strongly associated number of years since the data describing on that species, followed by scientific capacity within the range of species, high body mass and invasiveness. The threat-status was weakly associated to explain the presence/absence and research volume in conservation research. These results can be interpreted as a consequence of the dynamic interplay between the perceived need for conservation research about a species and its appropriateness as a target of research. As anticipated, the scientific capacity of the countries where a species is found is a strong driver of conservation research bias, reflecting the high variation in conservation research funding and human resources between countries. Our study suggests that this bias could be most effectively reduced by a combination of investing in pioneering research, targeted funding and supporting research in countries with low scientific capacity and high biodiversity. 
42 Key-words: Taxonomic Bias, Knowledge Production, Biodiversity Conservation, Mammals Introduction

'Saving' species from extinction is a central objective of the global conservation movement and a focal point for conservation actions (Adams, 2013). Success in this endeavour requires at least three general conditions to be fulfilled: i) species need to be described and identified as being at risk of extinction, through processes such as the IUCN's Red List assessment (Rodrigues et al., 2006); ii) there should be sufficient biological, ecological and cultural knowledge of the species to support the design and implementation of appropriate conservation interventions (Cooke et al., 2017; Murray et al., 2015; Sutherland et al., 2004), and; iii) conservation groups with the technical capacity, financial resources and willingness to intervene should be present within the geographic region occupied by the species (Ladle and Jepson, 2008). Scientific knowledge is central to the first two conditions and is often a fundamental component of effective conservation actions (Sutherland et al., 2004). Of course, more knowledge does not always lead to better conservation or swifter action, but ceteris paribus adequately studied species are more likely to be the recipients of effective conservation actions.

It is well known that scientific knowledge of species is extremely patchy, both taxonomically and spatially (Clark and May, 2002; Fleming and Bateman, 2016; Murray et al., 2015; Meyer et al., 2015) with potentially serious consequences for conservation. For example, even if a species is identified as being threatened, a lack of scientific knowledge can seriously impede the development of effective conservation interventions. The importance of scientific knowledge is reflected in Aichi Target 19, that identifies the improvement of "scientific knowledge about biodiversity and its applicability in decision-making" as a key enabling condition for the development of the Strategic Plan for Biodiversity (Marques et al., 
2014). Scientific knowledge also has a broader role in conservation, helping the public to understand the need for protection and why certain policies (e.g. eradication of invasive species) are favoured over others (Dreyfus, 1995).

The reasons for the extreme patchiness of scientific knowledge about species are complex, reflecting factors such as an unequal allocation of resources, spatial and temporal variation in research capacity, and the intrinsic characteristics of a species that makes it an convenient target for a particular type of research project (Clark and May, 2002). In this context, 'appropriateness' reflects both the extent of existing knowledge (both generally and specific to the individual/research group) and the difficulty of collecting new data. This latter characteristic is, in turn, dependent upon the ecological characteristics of the species and their geographical distribution.

Some of the factors that could influence whether a given species is the subject of research (e.g. cultural preferences, availability of local research funding, research history, etc.) vary enormously in time and space and are therefore difficult to systematically assess at a global level. However, other factors (e.g. country level research capacity, species range size, etc.) should be more temporally stable and, for that reason, are likely to be the main drivers of the observed systematic taxonomic biases in conservation research (Clark and May, 2002). For example, all things being equal, we would predict an endemic species in a country with low scientific capacity to be less studied (be the subject of fewer scientific articles) than an ecologically equivalent (e.g. in terms of body size, range size, habitat, etc.) endemic species in a more scientifically developed country. This is because: i) scientists tend to study species within the country where they work due to a combination of funding priorities, cost and practical convenience, and; ii) countries with low scientific capacity probably have fewer qualified scientists and less resources available for research. Thus, we would predict a strong 
90 influence of geography on taxonomic bias in conservation research effort (Fisher et al., 2011;

Meyer et al., 2015; Hortal et al., 2016).

Another group of systematic biases is associated with the 'researchability' of a species, defined here as any characteristic of the species that potentially increases the costs of data collection or which impedes or reduces the feasibility of a research project. For field-based conservation research this includes any characteristics that make a species more difficult to observe, such as small body size, nocturnal activity patterns (Chetana and Ganesh, 2007), elusiveness (Lampa et al., 2015) or cryptic coloration (Vine et al., 2009). Such issues may be particularly problematic for academics whose career advancement strongly depends on their publication records or students who need to meet dissertation requirements (Caro, 2007), and could conceivably act as a disincentive to choose certain species as the subjects of a research project. Moreover, researchability may also be influenced by geographical factors such as range size or remoteness (Ladle et al., 2011) since these can considerably increase research costs and feasibility (depending on resources and technical equipment requirements). The importance of some of these systematic biases has been well studied in relation to the collection of biological samples, whose distribution is often highly correlated with the presence of roads or proximity to research centres (e.g. Reddy and Dávalos, 2003; Kuper et al., 2006; Stropp et al., 2016). More recently, a regional scale bibliometric analysis of Australian birds showed that there were significantly more publications on species with larger body sizes, larger ranges, higher relative abundance, and which can be found in urban environments (Yarwood et al., 2019).

Finally, given that conservation science is both globalized and mission-orientated (Jepson and Canney, 2003), we would also predict that conservation scientists around the world would also respond to conservation need (as indicated by global conservation priority 
114 classifications). At a species level, the most commonly used prioritization system is the

115 IUCN Red List of endangered species (Rodrigues et al., 2006) which classifies species into

116 endangerment categories based on a combination of demographic and geographic

117 characteristics. We might, therefore, predict that individual researchers and funding agencies

118 (national and international) might respond to this categorization by prioritizing research on

119 endangered species (Rodrigues et al., 2006). It should be noted that endangered species may

120 also be among the least 'researchable', since they are by definition often difficult to locate,

121 observe and study (Pawar, 2003). These conflicting drivers may explain why a recent

122 bibliometric analysis of felids and canids failed to find any influence of conservation status

123 on the volume of published conservation research (Tensen, 2018).

124 In summary, it is clear that various factors influence taxonomic bias in research and that perceived conservation need may not always be the overriding priority when a conservation researcher chooses to work on a particular species, leading to a potential mismatch between what species are actually being studied and what species we most need to know about. Here, we explore this issue by developing the first quantitative model of global conservation science knowledge for non-marine terrestrial mammal species. We chose terrestrial mammals because they are large and highly culturally visible taxon whose species vary considerably in ecological and biogeographical attributes. Moreover, research on mammal conservation has received more attention from researchers in comparison to other vertebrate groups, although this attention is not evenly distributed among taxa (Clark and May, 2002). Specifically, we use our model to quantify the relative importance of factors associated with conservation need (e.g. threat status, endemism) and the more prosaic and pragmatic factors that make some species easy and cheaper to research (e.g. large range size, diurnal behaviour, etc.). 
Materials and Methods

140 We originally considered all non-marine mammal species present in the IUCN Red List 141 (version 2017.1). For each of the 5,346 mammal species on this list, we aimed to collect 142 information on the currently accepted scientific names and any synonyms to guarantee the adequate retrieval of information available in digital databases (Correia et al., 2017; Correia et al. 2018; Remsen, 2016). However, we were unable to identify one or more explanatory variables (see below) for 1,238 species, 734 of which are classified as Data-Deficient by the IUCN Red List. These species were consequently excluded from our final analysis, which considered a total of 4,108 non-marine mammal species.

Dependent Variable

We quantified the conservation science research effort for each mammal species in our database through the number of scientific publications (including research articles, reviews, notes, book chapters, and other peer reviewed documents) indexed by Clarivate Analytics' Web of Science (WoS) platform. We attributed published documents to species by searching for scientific names and any known scientific synonyms (e.g. "Mus musculus" OR "Mus domesticus") in a topic search (covering titles, abstracts and keywords). We searched using scientific names because we reasoned that if a species name appears in the title, abstract or keywords then it is likely that the publication contains significant information about that species. Clearly, a proportion of published documents will mention the species name and little relevant information while other documents may be relevant, but not be captured by our search terms. While this reduces the precision of the results, our search method is replicable and should be taxonomically unbiased, allowing for the identification of broad-scale patterns. 
162 Data were collected between January and April of 2017 and the number of documents 163 published between 1945 and 2016 returned by each search were recorded. After this, we

164 filtered results for WoS's "Biodiversity Conservation" topic (excluding documents that did 165 not appear in conservation-themed journals), and used this as our metric of conservation166 relevant knowledge.

167 It should also be noted that the published documents in our study represent only a proportion of the research conducted for any given project, and that many research projects may never generate a peer-reviewed publication. Of course, there are many reasons that a conservation scientist may not publish, including: i) insufficient evidence (e.g. observations of a rare species) to construct a convincing narrative; ii) lack of significant results; iii) research that is too local or descriptive to be easily published, and; iv) lack of capacity and/or interest on the part of the project team. Some of this information ends up in non-peer reviewed scientific products such as undergraduate theses and expedition reports, and much of it ends up in the file drawers and computers of scientists. Many of the above factors are more likely to be associated with a rare/threatened species potentially pushing conservation scientists to choose study species that have greater potential for generating a publication (Caro, 2007).

\section{Explanatory variables}

To better understand the factors influencing variability in conservation research between species, we identified two main factors that could influence taxonomic bias in conservation research on mammals: 
Conservation need: researchers may respond to perceived conservation need, such as species identified as at risk of extinction (Rodrigues et al., 2006), threats to the existence of other species (Clavero and García-Berthou, 2005), or the intrinsic value of their evolutionary distinctiveness (Isaac et al., 2007; Jetz et al., 2014);

Researchability: Some mammal species are easier than others to find, observe, manipulate and write about due to: i) intrinsic characteristics such as body size, diurnality, habitat use and population density (Ladle et al., 2011) and; ii) geographic factors that are extrinsic to the species, such as the overlap between the distribution of scientists and that of the species they study (Meyer et al., 2015), i.e. a species may have intrinsic characteristics that facilitate research, but there may be limited local capacity to take advantage of this. At an international level we would predict that species in countries with high conservation science capacity would be more studied than those distributed in countries with lower capacity (Fisher et al., 2011). Finally, science is iterative, and we would therefore expect that a priori knowledge of a species (e.g. volume of historical research) will facilitate the development of innovative science which may be more easily published in peer-reviewed journals.

We represented these factors in our model with the following proxy variables (See Table 1 for details): i) Conservation need: conservation threat status (Baillie et al., 2004); introduced species; evolutionary distinctiveness, which is a measure of species exclusivity; ii) Researchability: range size $(\log 10+1)$, environmental science capacity within the countries where the species is present, nocturnal habit, body mass $(\log 10+1)$, years since species description (Table 1). 
Data analysis

210 We explored the relationship between the different explanatory variables and research

211 productivity at the species level using a hurdle model analysis for zero-inflated count data

212 (Zeileis et al., 2008). Hurdle models are two-component models composed of a zero-hurdle

213 component (henceforth Zero-hurdle model) that models the probability of counts being zero

214 or not, and a truncated count component (henceforth Count model) that is applied to positive

215 counts (i.e. those > 0). This modelling approach was chosen due to the high number of

216 species without any recorded study. This approach is not only more adequate to model zero-

217 inflated data than standard Generalized Linear Models, it also allows for modelling the effect

218 of each explanatory variable on both the presence or absence of research on mammals and the

219 amount of research for each species with at least one scientific product.

220 Due to the large number of variables than can plausibly influence a scientist's decision to work on a particular species, it is unlikely that a single model can accurately represent such a complex decision-making process. We therefore decided to adopt a multi-model inference approach, which allows us to calculate a weighted-average estimate of the effect of each explanatory variable based on the most plausible hypothesis explaining the decision process (Burnham and Anderson, 2004; Burnham et al., 2011). Hence, we calculated all possible model combinations considering our set of explanatory variables and identified the set of most plausible models according to AIC corrected for small sample size (AICc) and considered all models with a $\triangle \mathrm{AICc} \leq 4$ in relation to the best model (Table S1) for a conditional-model averaging process. Each continuous variable was standardized before inclusion in the models (Schielzeth, 2010), so that their relative effect size could be considered a measure of relative importance explaining species-level scientific interest. 
All model assumptions were tested prior to analysis (Zuur et al., 2010) and variable multicollinearity was assessed; we found no evidence that assumptions were not met and no evidence of strong correlation (Spearman's correlation; $r \leq|0.7|$ ) between variables. Hurdle regression models were implemented using the function 'hurdle' of the package 'pscl' and every model combination examined with the 'MuMIn' package (Barton, 2009) within the R platform (R Core Team, 2013).

\section{Results}

240 Our searches on WoS for the scientific names and synonyms of 4,108 non-marine mammal 241 species resulted in a total of 95,420 published documents in journals in the Biodiversity

242 Conservation area. Approximately $20 \%$ of these documents were associated with the 10 most-researched mammal species; Sus scrofa (wild boar), Odocoileus virginianus (whitetailed deer), Cervus elaphus (red deer), Canis lupus (grey wolf), Vulpes vulpes (red fox), Alces alces (moose), Loxodonta africana (African elephant), Odocoileus hemionus (mule deer), Rangifer tarandus (reindeer) and Ursus arctos (brown bear), respectively (Figure 1).

In contrast, almost $76 \%$ of the studied species were associated with 10 documents or less, representing about $8 \%$ of all documents. That is, almost a quarter of species studied were associated with about $92 \%$ of all documents. Moreover, approximately a quarter of species were not have any document in the WoS database. At the order level, approximately $99 \%$ of published documents were associated with species belonging to less than half of extant mammalian orders (Fig. S1). Species in the three most studied orders, Cetartiodactyla, Carnivora and Rodentia were associated with $70 \%$ of all documents. Note, some documents on Sus scrofa relate to work on domestic pigs (Sus scrofa domesticus), since these occasionally relevant in conservation-related studies. 
Our hurdle analysis clearly shows that even though we focused on conservation-related articles, variables representing 'researchability' were the most important determinants of whether a mammal species had any associated articles in our database. Specifically, scientific capacity of countries within the range of a species was the most important variable explaining

260 the presence/absence of conservation research. Body mass and years since taxonomic 261 description were also associated with species with one or more associated document. 'Conservation need' as measured by threat-status was only weakly associated with research effort, while evolutionary distinctiveness and nocturnality had no relationship with presence/absence of published research (Fig. 2). The results of the most parsimonious hurdle models reinforce the findings that threat status, evolutionary distinctiveness and nocturnality have a negligible influence on whether a species has been the subject of published research (Table 2). Invasiveness was not included in the Zero-hurdle part of the analysis because all species with this characteristic were associated with at least one published document in the database.

For species that had one or more associated scientific documents, the average of most parsimonious models (Table S1) indicates that all variables have, to a greater or lesser degree, a significant influence. The most important variable explaining the volume of scientific documents (more than one document) was the number of years since the data describing on that species (Fig. 2, Table 2). Scientific capacity of range countries, high body mass and invasiveness also had a strong positive association with the number of scientific documents.

276 Nocturnality, threat status and range size were weakly associated with research volume and evolutionary distinctiveness had a negative association.

\section{Discussion}


280 Our most general finding is that conservation research on mammals shows dramatic 281 taxonomic biases, broadly confirming the conclusions of previous studies (Clark and May, 282 2002; Donaldson et al., 2016; Fazey et al., 2005a; Tensen, 2018). More than a quarter of 283 species in our database were associated with few or no published documents on WoS. While 284 this is probably an accurate and relatively unbiased reflection of the relative taxonomic 285 distribution of conservation research on mammals, it is important to acknowledge that our metric does not capture all conservation knowledge. There is a wealth of information in the grey literature and in non-text sources, although we would argue that, ceteris paribus, there is likely to be a strong correlation between the volume of published and unpublished literature about a given species (De Lima et al., 2011). Similarly, recent studies have shown strong and consistent correlations between the frequency of use of species vernacular and scientific names on the internet, in newspapers and on social media networks (Jarić et al., 2016; Correia et al., 2017), even though the latter are mainly restricted to technical documents.

The reasons for such a highly skewed distribution of conservation research are undoubtedly both complex and interacting. Scientists might be actively avoiding working on rare and understudied species. Limited resources (Wilson et al., 2006) and pressure to publish could encourage risk-averse behaviour of conservation scientists and funders, who may be unwilling to invest in the development of new study systems. For example, Tim Caro recently observed a growing tendency of graduate students studying animal behavior to work on common species that are considered to be ecologically similar to a species of conservation concern (Caro, 2017). Caro attributes this trend to the fact that rare species are "difficult to locate and result in small sample sizes" (Caro, 2017), which presumably leads to poorly substantiated studies that are difficult to publish. Such risk-averseness may have contributed to the large number of studies on introduced species (which are often abundant and easy to 
study) in our database. More broadly, there may often be a conflict between what needs to be studied (because it is endangered) and the career aspirations of the researcher who may need to publish in prestigious journals.

Another factor that could potentially increase taxonomic bias is geographic biases in research capacity. Indeed, environmental science capacity of countries within the range of a species was strongly associated with research effort for both components of our Hurdle model. This is most simply explained as a consequence of conveniently located study populations overlapping with a qualified 'corpus' of conservation researchers (Fazey et al., 2005b; Meyer et al., 2015; Ibáñez-Álamo et al., 2017). Such a consequence inevitably leads to a mismatch between conservation research effort and conservation research need which is higher in the world's most biodiverse countries in the global south (Fisher et al., 2011). This finding parallels several studies that have shown a strong geographic correlation between the presence of a research centres and a high density of biological records and conservation research (e.g. Amano and Sutherland, 2013; Engemann et al., 2015; Ibáñez-Álamo et al., 2017; Schulman et al., 2007; Lessa et al., 2019; Correia et al., 2019). Such geographical biases in research are likely to be reduced in the future if few research capacity countries invest greater amounts of resources in science (Fazey et al., 2005b) and consequently insert more conservation qualified researchers in areas with low research capacity However, it is unlikely that such biases will ever be eliminated given our finding that the number of years since the first published study was strongly correlated with research volume. This result reflects the iterative nature of scientific research, with previous studies providing context, baselines and inspiration for future studies (dos Santos et al., 2015). In other words, the more a species is researched, the more it will be researched. 
Body size was also strongly associated with both presence and volume of

conservation research. That larger species are frequently more studied has previously been noted (Ibáñez-Álamo et al., 2017; Tensen, 2018), and may be related to their higher cultural profile (Frynta et al., 2013; Jepson and Barua, 2015; Macdonald et al., 2015; Ladle et al., 2019), and that they are more likely to be hunted, have lower population densities, slower life histories and, consequently, to be at greater risk of extinction (Schipper et al., 2008). Additionally, large species are often more conspicuous and may be easier to study in situ. They also appear to attract more attention to both scientists and citizens, and thus can be used to mobilize resources for research and conservation (Brodie, 2009; Frynta et al., 2013).

Another of our results was the strong association between the time since a species was scientifically named and conservation research volume. This may be related to the contrasting biocultural traits of the first mammals to be described in comparison to more recently discovered species. The former tended to be from Europe where most of the early taxonomists lived and worked, or were sufficiently impressive or culturally important to have come to the attention of these taxonomists.

From a conservation perspective, the association between threat category and presence and volume of scientific documents suggests that conservation science research is responding, albeit weakly, conservation need. This is especially encouraging given that endangered species will frequently be more difficult to study due to low densities and population sizes, and because their study may entail additional bureaucratic hurdles (Berenbaum, 2008; Strier and Mendes, 2009). Our results suggest the act of listing (e.g. IUCN Red Lists, EDGE or CITES appendices) may provide scientists with additional justifications for engaging in new research projects on a species. 
The above result is at variance with a recent study on European birds that concluded that "research effort was not well targeted with respect to either European or global threat status" (Murray et al., 2015, p. 193). Likewise, Amori and Gippoliti (2000) analyzed the scientific articles present in four important international conservation journals (Oryx, Conservation Biology, Biological Conservation and Biodiversity and Conservation) and concluded that there was a lower research effort associated with more threatened species of mammals. A study on British breeding birds also found that species with declining range size were less studied based on ecology publications (McKenzie and Robertson, 2015). For Canidae (Tensen, 2018) and Felidae (Brodie, 2013) families, threat status also had no significance in relation to other variables in the search allocation effect, such as body mass. However, the conservation-focused research appears to target endangered island endemic bats, although there was no greater research attention with the increased risk of extinction of these species (Conenna et al., 2017). These discrepancies are potentially caused by the smaller taxonomic or geographic scale of some of the studies and the different ways of measuring research effort.

It is important to reiterate that there are a number of factors that may significantly influence conservation research on mammals, but were not included in our model because they are either: i) locally important, but are expected to have little influence at a global level, or ii) are difficult to systematically quantify. A possible example of the former is national level funding priorities that target certain endangered or iconic species. An example of the latter are traits associated with species charisma (Lorimer, 2007) or aesthetic appeal (Lišková and Frynta, 2013). Species with such traits often benefit from increased public interest, making them excellent candidates for flagship species or as the subject of conservation fundraising campaigns (Clucas et al., 2008; Jepson and Barua, 2015). Interestingly, 
374 charismatic species may also be highly threatened, possibly because the public are so familiar with representations of these species that they assume that they must have healthy populations (Courchamp et al., 2018). However, aesthetic appeal cannot be easily quantified at scale, although this may soon change with the development of increasingly sophisticated tools to quantify different dimensions of human interest in wild species and nature ( $c f$. Ladle et al., 2016).

Species charisma is not the only driver of human interest in non-human species, and another factor that could influence research effort is their degree of similarity (physical or otherwise) with humans. Such anthropomorphism, in addition to promoting empathy with non-human species (Chan, 2012) could also act to encourage research. Moreover, while anthropomorphism itself is hard to systematically quantify, a recent social survey found that empathy towards a variety of non-human species was inversely related to evolutionary divergence times from the human lineage (Miralles et al., 2019), potentially opening a path to incorporate a broad proxy of anthropomorphism/empathy into macroscale studies of human interest in nature. It should noted, however, that while charisma and anthropomorphic traits clearly relate to human interest, their impact on research may be much less marked. This is supported by a recent study by Troudet et al. (2017) who showed that societal preferences (as measured by internet searches) were a much better predictor of taxonomic bias in biodiversity information (measured by GBIF records) than was research effort. mean that a species that has already been well researched becomes a 'better' subject for future research. Such positive feedback could, over time, act to increase inequalities between species in terms of research effort and publications. If such an effect is operating, it places exceedingly high value on pioneer research, which can form the basis for future, more 
sophisticated research. Interestingly, there is good evidence that pioneer research also boosts research effort in geographic regions (Dos Santos et al., 2015) and in protected areas (Correia et al., 2016).

\section{Conclusions}

Most conservation scientists would agree that choice of research organism is of fundamental importance, influencing research and conservation outcomes, societal relevance, future funding opportunities and even personal motivation and job satisfaction. Nevertheless, such choices are also strongly constrained by professional requirements for high impact research, accessing existing funding streams and practical considerations such as access to conveniently situated field sites. Not only does this lead to the well-known pattern of taxonomic bias in conservation research (Clark and May, 2002), it strongly suggests that such bias is structural and will not be easily remedied. Well-studied species will continue to be the best models for sophisticated research requiring international journals. Thus, additional incentives are required for species that are poorly researched and largely ignored by researchers. Our research indicates that these species are typically small, present in countries with low scientific capacity, have restricted geographic distributions, have not been introduced elsewhere, and have often been described recently and are evolutionarily distinct. This highlights the importance of increasing dedicated incentives to work on poorly known species (e.g. dedicated funding streams, sympathetic journal editors, changes in evaluation systems for researchers, etc). Such incentives have added importance given that new species discoveries and taxonomic revisions are likely to add to the global total of poorly known species and gradually fill the knowledge gaps over time (Hortal et al., 2015). In addition to ensuring dedicated funding streams for poorly known taxa, it will also be important invest in 
ecological surveying and taxonomy which, while unlikely to generate many high impact publications, will produce invaluable baseline data for conservation decision making and provide a start point for future studies.

\section{Acknowledgments}

The authors would like to thank Bruno Umbelino and Thainá Lessa for discussions. This work was funded by the Brazilian National Council for Scientific and Technological

Development CNPq with research grants to PJ-RJL (\#400325/2014-4 and \#448966/2014-0).

JWS's dissertation was funded by Coordination for the Improvement of Higher Education

Personnel CAPES-Brazil. RAC was initially supported by a CNPq post-doctoral grant

(\#158841/2015-8) and is currently funded by post-doctoral scholarship from FCT - Fundação para a Ciência e Tecnologia (SFRH/BPD/118635/2016). RJL and ACMM are funded by

Author Contributions: Conceived and designed the study: RJL ACCM JWS RAC JVC-S.

Collected the dataset: JWS. Analysed the data: JWS JVC-S DT RAC. Wrote the article: JWS RJL RAC ACMM JVC-S DT PJ.

\section{References}

Adams, W. B. (2013). Against extinction: The story of conservation. Oxford: Routledge.

Amano, T., Sutherland, W. J. (2013). Four barriers to the global understanding of biodiversity conservation: Wealth, language, geographical location and security. Proceedings of the Royal 444 Society B 280, 20122649.

Amori, G., Gippoliti, S. (2000). What do mammalogists want to save? Ten years of 
447 Baillie, J., Hilton-Taylor, C., Stuart, S. N. (Eds.) (2004). Iucn red list of threatened species: A

448 global species assessment. Gland, Switzerland: IUCN.

449 Barton, K. (2009). Mumin: Multi-model inference. R package version 1. 0. 0. http://r-forge.

$450 \quad$ r-project. org/projects/mumin/.

451 Berenbaum, M. (2008). Insect conservation and the entomological society of america. 452 American Entomologist 54, 117.

453 Brodie, J. F. (2009). Is research effort allocated efficiently for conservation? Felidae as a 454 global case study. Biodiversity and Conservation 18, 2927.

455 Burnham, K. P., Anderson, D. R. (2004). Multimodel inference: Understanding aic and bic in 456 model selection. Sociological methods \& research 33, 261.

457 Burnham, K. P., Anderson, D. R., Huyvaert, K. P. (2011). Aic model selection and 458 multimodel inference in behavioral ecology: Some background, observations, and 459 comparisons. Behavioral Ecology and Sociobiology 65, 23.

460 Caro, T. (2007). Behavior and conservation: a bridge too far? Trends in Ecology \& Evolution $461 \quad 22,394$.

462 Cassey, P., Blackburn, T. M. (2003). Publication rejection among ecologists. Trends in 463 Ecology \& Evolution 18, 375.

464 Chan, A. A. H. (2012). Anthropomorphism as a conservation tool. Biodiversity and 465 Conservation 21, 1889.

466 Chetana, H. C., Ganesh, T. (2007). Survey and activity patterns of nocturnal mammals in a 467 fragmented dry deciduous forest of Karnataka. Zoo's Print Journal 22, 2644.

468 Clark, J. A., May, R. M. (2002). Taxonomic bias in conservation research. Science 297, 191.

469 Clavero, M., García-Berthou, E. (2005). Invasive species are a leading cause of animal 470 extinctions. Trends in Ecology \& Evolution 20, 110.

471 Clucas, B., McHugh, K., Caro, T. (2008). Flagship species on covers of US conservation and nature magazines. Biodiversity and Conservation 17, 1517.

473 Colléony, A., Clayton, S., Couvet, D., Jalme, M. S., Prévot, A. (2017). Human preferences 474 for species conservation: Animal charisma trumps endangered status. Biological conservation $475 \quad 206,263$.

476 Conenna, I., Rocha, R., Russo, D., Cabeza, M. (2017). Insular bats and research effort: a 477 review of global patterns and priorities. Mammal Review 47, 169. doi:10.1111/mam.12090.

478 Cooke, S. J., Birnie-Gauvin, K., Lennox, R. J., Taylor, J. J., Rytwinski, T., Rummer, J. L., 479 Franklin, C. E., Bennett, J. R., Haddaway, N. R. (2017). How experimental biology and 
ecology can support evidence-based decision-making in conservation: Avoiding pitfalls and enabling application. Conservation Physiology 5.

Correia, R. A., Jaric, I., Jepson, P., Malhado, A. C. M., Alves, J. A., Ladle, R. J. (2018). Nomenclature instability in species culturomic assessments: Why synonyms matter. Ecological indicators 90, 74.

Correia, R. A., Jepson, P., Malhado, A. C. M., Ladle, R. J. (2017). Internet scientific name frequency as an indicator of cultural salience of biodiversity. Ecological indicators 78, 549.

Correia, R. A., Malhado, A. C. M., Lins, L., Gamarra, N. C., Bonfim, W. A. G., ValenciaAguilar, A., Bragagnolo, C., Jepson, P., Ladle, R. J. (2016). The scientific value of amazonian protected areas. Biodiversity and Conservation 25, 1503.

Courchamp, F., Jaric, I., Albert, C., Meinard, Y., Ripple, W. J., Chapron, G. (2018). The paradoxical extinction of the most charismatic animals. Plos Biology 16, e2003997.

De Lima, R. F., Bird, J. P., \& Barlow, J. (2011). Research effort allocation and the conservation of restricted-range island bird species. Biological Conservation 144, 627. doi:10.1016/j.biocon.2010.10.021.

De Silva, P. U., Vance, C. K. (2017). Measuring the impact of scientific research. In Scientific scholarly communication: The changing landscape: 101-115. De Silva, P. U., Vance, C. K. (Eds.). Cham, Switzerland: Springer.

Donaldson, M. R., Burnett, N. J., Braun, D. C., Suski, C. D., Hinch, S. G., Cooke, S. J., Kerr, J. T. (2016). Taxonomic bias and international biodiversity conservation research. FACETS 1 , 105.

Dreyfus, A. (1995). Biological knowledge as a prerequisite for the development of values and attitudes. Journal of Biological Education 29, 215.

Engemann, K., Enquist, B. J., Sandel, B., Boyle, B., Jørgensen, P. M., Morueta-Holme, N., Peet, R. K., Violle, C., Svenning, J. (2015). Limited sampling hampers "big data" estimation of species richness in a tropical biodiversity hotspot. Ecology and Evolution 5, 807.

Fazey, I., Fischer, J., Lindenmayer, J. D. B. (2005a). What do conservation biologists publish? Biological Conservation 124, 63.

Fazey, I. et al. (2005b). Who does all the research in conservation biology? Biodiversity \& Conservation 14, 917.

Fisher, R., Radford, B. T., Knowlton, N., Brainard, R. E., Michaelis, F. B., Caley, M. J. (2011). Global mismatch between research effort and conservation needs of tropical coral reefs. Conservation Letters 4, 64.

Fleming, P. A., Bateman, P. W. (2016). The good, the bad, and the ugly: Which australian terrestrial mammal species attract most research? Mammal Review 46, 241. 
515 Frynta, D., Šimková, O., Lišková, S., Landová, E. (2013). Mammalian collection on noah's 516 ark: The effects of beauty, brain and body size. PLoS One 8, e63110.

517 Haddaway, N. R., Bayliss, H. R. (2015). Shades of grey: Two forms of grey literature 518 important for reviews in conservation. Biological Conservation 191, 827.

519 Hortal, J., de Bello, F., Diniz-Filho, J. A. F., Lewinsohn, T. M., Lobo, J. M., Ladle, R. J. 520 (2015). Seven shortfalls that beset large-scale knowledge of biodiversity. Annual Review of 521 Ecology, Evolution, and Systematics 46, 523.

Ibáñez-Álamo, J. D., Rubio, E., Bitrus Zira, K. (2017). The degree of urbanization of a species affects how intensively it is studied: A global perspective. Frontiers in Ecology and Evolution 5, 41.

Isaac, N. J., Turvey, S. T., Collen, B., Waterman, C., Baillie, J. E. (2007). Mammals on the edge: Conservation priorities based on threat and phylogeny. PloS one 2, e296.

Jarić, I., Courchamp, F., Gessner, J., Roberts, D. L. (2016). Data mining in conservation research using Latin and vernacular species names. PeerJ 4, e2202.

Jepson, P., Canney, S. (2003). Values-led conservation. Global Ecology and Biogeography $12,271$.

Jepson, P., Barua, M. (2015). A theory of flagship species action. Conservation and Society 13,95 .

Jetz, W., Thomas, G. H., Joy, J. B., Redding, D. W., Hartmann, K., Mooers, A. O. (2014). $24,919$.

Koricheva, J. (2003). Non-significant results in ecology: A burden or a blessing in disguise? Oikos 102, 397.

Küper, W., Sommer, J. H., Lovett, J. C., Barthlott, W. (2006). Deficiency in african plant distribution data-missing pieces of the puzzle. Botanical Journal of the Linnean Society 150, 355 .

Ladle, R., Jepson, P., Malhado, A. C. M., Jennings, S., Barua, M. (2011). The causes and biogeographical significance of species' rediscovery. Frontiers of Biogeography 3, 104.

Ladle, R. J., Jepson, P. (2008). Toward a biocultural theory of avoided extinction. Conservation Letters 1, 111.

548 Ladle, R. J., Jepson, P., Correia, R. A., Malhado, A. C. M. (2019). A culturomics approach to 549 quantifying the salience of species on the global internet. People \& Nature 00, 1. 
Lampa, S., Mihoub, J-B., Gruber, B., Klenke, R., Henle, K. (2015). Non-invasive genetic mark-recapture as a means to study population sizes and marking behaviour of the elusive Eurasian Otter (Lutra lutra). PloS one 10, e0125684.

Lessa, T., dos Santos, J. W., Correia, R. A., Ladle, R. J., Malhado, A. C. M. (2019). Known unknowns: Filling the gaps in scientific knowledge production in the Caatinga. PloS one 14, e0219359.

Lišková, S., Frynta, D. (2013). What determines bird beauty in human eyes? Anthrozoös 26, 27.

Lorimer, J. (2007). Nonhuman charisma. Environment and Planning D: Society and Space 25, 911.

Marques, A., Pereira, H. M., Krug, C., Leadley, P. W., Visconti, P., Januchowski-Hartley, S. R., Krug, R. M., Alkemade, R., Bellard, C., Cheung, W. W. L., Christensen, V., Cooper, H. D., Hirsch, T., Hoft, R., van Kolck, J., Newbold, T., Noonan-Mooney, K., Regan, E. C., Rondinini, C., Sumaila, U. R., Teh, L. S. L., Walpole, M. (2014) A framework to identify enabling and urgent actions for the 2020 Aichi Targets. Basic and Applied Ecology 15, 633.

McKenzie, A. J. , Robertson, P. A. (2015). Which species are we researching and why? A case study of the ecology of british breeding birds. PloS one 10, e0131004.

Meyer, C., Kreft, H., Guralnick, R., Guralnick, R., Jetz, W. (2015) Global priorities for an effective information basis of biodiversity distributions. Nature Communications 6, 8221 .

Miralles, A., Raymond, M., Lecointre, G. (2019). Empathy and compassion toward other species decrease with evolutionary divergence time. Scientific Reports 9, 1-8.

Murray, H. J., Green, E. J., Williams, D. R., Burfield, I. J., Brooke, M. de L. (2015). Is research effort associated with the conservation status of european bird species? Endangered Species Research 27, 193.

Pawar, S. (2003). Taxonomic chauvinism and the methodologically challenged. Bioscience 53,861 .

R Core Team (2013). R: A language and environment for statistical computing.

Reddy, S., Dávalos, L. M. (2003). Geographical sampling bias and its implications for conservation priorities in africa. Journal of Biogeography 30, 1719.

Remsen, D. (2016). The use and limits of scientific names in biological informatics. ZooKeys $550,207$.

Rodrigues, A. S., Pilgrim, J. D., Lamoreux, J. F., Hoffmann, M., Brooks, T. M. (2006). The value of the IUCN red list for conservation. Trends in Ecology \& Evolution 21, 71.

Schielzeth, H. (2010). Simple means to improve the interpretability of regression coefficients. Methods in Ecology and Evolution 1, 103. 
585 Schipper, J., Chanson, J. S., Chiozza, F., et al. (2008). The status of the world's land and 586 marine mammals: Diversity, threat, and knowledge. Science 322, 225.

587 Schulman, L., Toivonen, T. , Ruokolainen, K. (2007). Analysing botanical collecting effort in 588 amazonia and correcting for it in species range estimation. Journal of Biogeography 34, 5891388.

590 Strier, K. B. , Mendes, S. L. (2009). Long-term field studies of south american primates. In 591 South american primates: 139-155: Springer.

592 Stropp, J., Ladle, R. J., Malhado, A. C. M., Hortal, J., Gaffuri, J., Temperley, W. H., Olav 593 Skøien, J., Mayaux, P. (2016) Mapping ignorance: 300 years of collecting flowering plants in 594 Africa. Global Ecology and Biogeography 25, 1085.

595 Sutherland, W. J., Pullin, A. S., Dolman, P. M., Knight, T. M. (2004). The need for evidence596 based conservation. Trends in Ecology \& Evolution 19, 305.

597 Tensen, L. (2018). Biases in wildlife and conservation research, using felids and canids as a 598 case study. Global Ecology and Conservation 15, e00423.

599 Troudet, J., Grandcolas, P., Blin, A., Vignes-Lebbe, R., Legendre, F. (2017). Taxonomic bias 600 in biodiversity data and societal preferences. Scientific Reports 7, 9132.

601 Vine, S. J., Crowther, M. S., Lapidge, S. J., Dickman, C. R., Mooney, N., Piggott, M. P., 602 English, A. W. (2009). Comparison of methods to detect rare and cryptic species: a case 603 study using the red fox (Vulpes vulpes). Wildlife Research 36, 436.

604 Wilson, K. A., McBride, M., Bode, M., Possingham, H. P. (2006). Prioritizing global 605 conservation efforts. Nature 440, 337.

606 Yarwood, M. R., Weston, M. A., Symonds, M. R. E. (2019). Biological determinants of 607 research effort on Australian birds: a comparative analysis. Emu-Austral Ornithology 119, 38.

608 Zeileis, A., Kleiber, C. , Jackman, S. (2008). Regression models for count data in R. Journal 609 of Statistical Software 27, 1.

610 Zuur, A. F., Ieno, E. N. , Elphick, C. S. (2010). A protocol for data exploration to avoid 611 common statistical problems. Methods in Ecology and Evolution 1, 3. 


\section{Table and Figure legends}

614 Table 1. Explanatory variables used to explain the number of scientific publications on 615 mammals. The table also provide a brief justification of why they were included and the source 616 where they were collected.

617 Table 2. Results of the Hurdle models relating conservation-themed scientific production to 618 proxy variables representing conservation need and researchability.

619 Figure 1. Relative volume of conservation-themed published documents for the 10 most 620 studied terrestrial species of mammals.

Figure 2. Coefficient estimates ( $\pm 95 \%$ confidence intervals) showing the magnitude and direction of effects of different variables on conservation published documents for the Hurdle model analysis. Coefficients are shown for the a) Zero-hurdle model component and the b) Count model component. Blue and red symbols represent positive and negative effects, respectively. Black symbols represent no effect. For full description of predictors, see SI. 
Table 1.

\begin{tabular}{|c|c|c|c|c|}
\hline Factor & Variable & Source & Level & Main Assumption \\
\hline \multirow{3}{*}{ Conservation Need } & Threat status & IUCN Red List $^{1}$ & $\begin{array}{l}\text { Threatened - } \\
\text { No threatened }\end{array}$ & $\begin{array}{l}\text { Researchers respond to } \\
\text { conservation need by working on } \\
\text { threatened species. }\end{array}$ \\
\hline & Introduced species & $\begin{array}{l}\text { IUCN Red List } \\
\text { GISD }^{3}\end{array}$ & $\begin{array}{l}\text { Introduced - } \\
\text { No introduced }\end{array}$ & $\begin{array}{l}\text { Researchers respond to } \\
\text { conservation need by working on } \\
\text { species which are a conservation } \\
\text { threat. }\end{array}$ \\
\hline & $\begin{array}{l}\text { Evolutionary } \\
\text { distinctiveness }\end{array}$ & $\begin{array}{l}\text { EDGE of } \\
\text { Existence }^{4}\end{array}$ & - & $\begin{array}{l}\text { Researchers work on more } \\
\text { evolutionarily distinct species } \\
\text { because they are more important } \\
\text { for conserving evolutionary } \\
\text { history. }\end{array}$ \\
\hline \multirow{5}{*}{ Researchability } & $\begin{array}{l}\text { Range size } \\
\left(\mathrm{km}^{2} ; \log 10+1\right)\end{array}$ & IUCN Red List $^{1}$ & - & $\begin{array}{l}\text { Species with broad geographic } \\
\text { ranges are more accessible to a } \\
\text { greater number of researchers. }\end{array}$ \\
\hline & Years since described & IUCN Red List ${ }^{1}$ & - & $\begin{array}{l}\text { Species discoveries earlier are } \\
\text { less likely to present a broad } \\
\text { baseline on which to base } \\
\text { additional studies. }\end{array}$ \\
\hline & $\begin{array}{l}\text { Mean body mass } \\
(g ; \log 10+1)\end{array}$ & $\begin{array}{l}\text { Elton traits } \\
\text { PanTHERIA }^{6} \\
\text { EoL }^{7} \\
\text { Primate Info Net } \\
\text { Animal } \\
\text { DiversityWeb } \\
\text { Mammal Species } \\
\text { of the World }\end{array}$ & - & $\begin{array}{l}\text { Larger species are, ceteris } \\
\text { paribus, easier to observe and } \\
\text { collect data on than smaller } \\
\text { species. }\end{array}$ \\
\hline & $\begin{array}{l}\text { Scientific capacity } \\
\text { (\% global } \\
\text { environmental science } \\
\text { publications } \\
\text { contributed by } \\
\text { countries in species' } \\
\text { range) }\end{array}$ & $\underline{\text { Scimago }^{11}}$ & - & $\begin{array}{l}\text { Countries with higher scientific } \\
\text { capacity are likely to have more } \\
\text { conservation scientists and } \\
\text { expend a greater research effort } \\
\text { per (native or introduced) species. }\end{array}$ \\
\hline & Nocturnality & $\begin{array}{l}\text { Elton traits } \\
\text { EoL }^{7}\end{array}$ & $\begin{array}{c}\text { Nocturnal - No } \\
\text { nocturnal }\end{array}$ & $\begin{array}{l}\text { Nocturnal species are generally } \\
\text { more difficult to observe and } \\
\text { study than diurnal species. }\end{array}$ \\
\hline
\end{tabular}

Data Souces: 1. www.iucnredlist.org/; 2. www.webofknowledge.com; 3. www.iucngisd.org/gisd; 4. www.edgeofexistence.org; 5. http://www.esapubs.org/archive/ecol/E095/178; 6 . http://esapubs.org/archive/ecol/e090/184/; 7. www.eol.org; 8. www.pin.primate.wisc.edu; 9. www.animaldiversity.org; 10. https://www.departments.bucknell.edu/biology/resources/msw3; 11. www.scimagojr.com/countryrank.php. 
Conservation Research Bias

636

Table 2.

\begin{tabular}{|c|c|c|c|c|c|}
\hline \multirow[b]{2}{*}{ Factor } & \multirow[b]{2}{*}{ Proxy Variables } & \multicolumn{2}{|c|}{ Zero-hurdle Model } & \multicolumn{2}{|c|}{ Count Model } \\
\hline & & $\begin{array}{c}\text { Rel. } \\
\text { Importance }\end{array}$ & $\begin{array}{l}\text { Nos. } \\
\text { Models }\end{array}$ & $\begin{array}{c}\text { Rel. } \\
\text { Importance }\end{array}$ & $\begin{array}{l}\text { Nos. } \\
\text { Models }\end{array}$ \\
\hline Researchability & Range size & 1 & 5 & 1 & 5 \\
\hline Researchasbility & Scientific Capacity & 1 & 5 & 1 & 5 \\
\hline Conservation Need & Introduced Species & - & - & 1 & 5 \\
\hline Conservation Need & Threat Status & 0.86 & 4 & 1 & 5 \\
\hline Conservation Need & Evol. Distinctiveness & 0.74 & 3 & 1 & 5 \\
\hline Researchability & Nocturnality & 0.24 & 2 & 1 & 5 \\
\hline Researchability & $\begin{array}{l}\text { Years since } \\
\text { Described }\end{array}$ & 1 & 5 & 1 & 5 \\
\hline Researchability & Body Mass & 1 & 5 & 1 & 5 \\
\hline
\end{tabular}

637

638 


$$
\text { illilı! }
$$


Conservation Research Bias

$657 \quad$ Figure 2

658
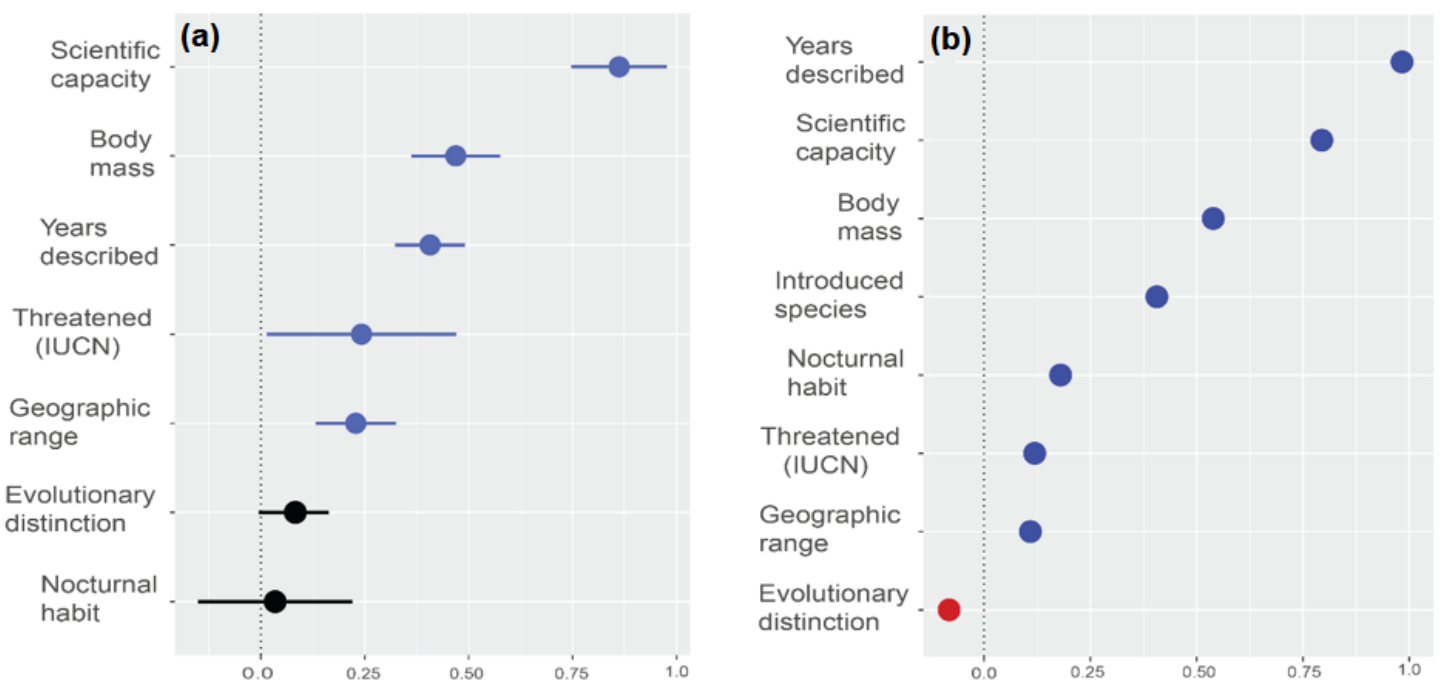

Regression coefficients $( \pm 95 \% \mathrm{Cl})$ 


\section{Conservation Research Bias}

\section{Supplementary material}

678 Figure S1. Relative value of conservation published documents for the 26 orders of 679 mammals. The colour standards per bar represent the relative values of published documents 680 for the distinct levels of threat. In the legend, "NO_THR" represents the non-threatened 681 species, while the "THR" represents the threatened species.

682

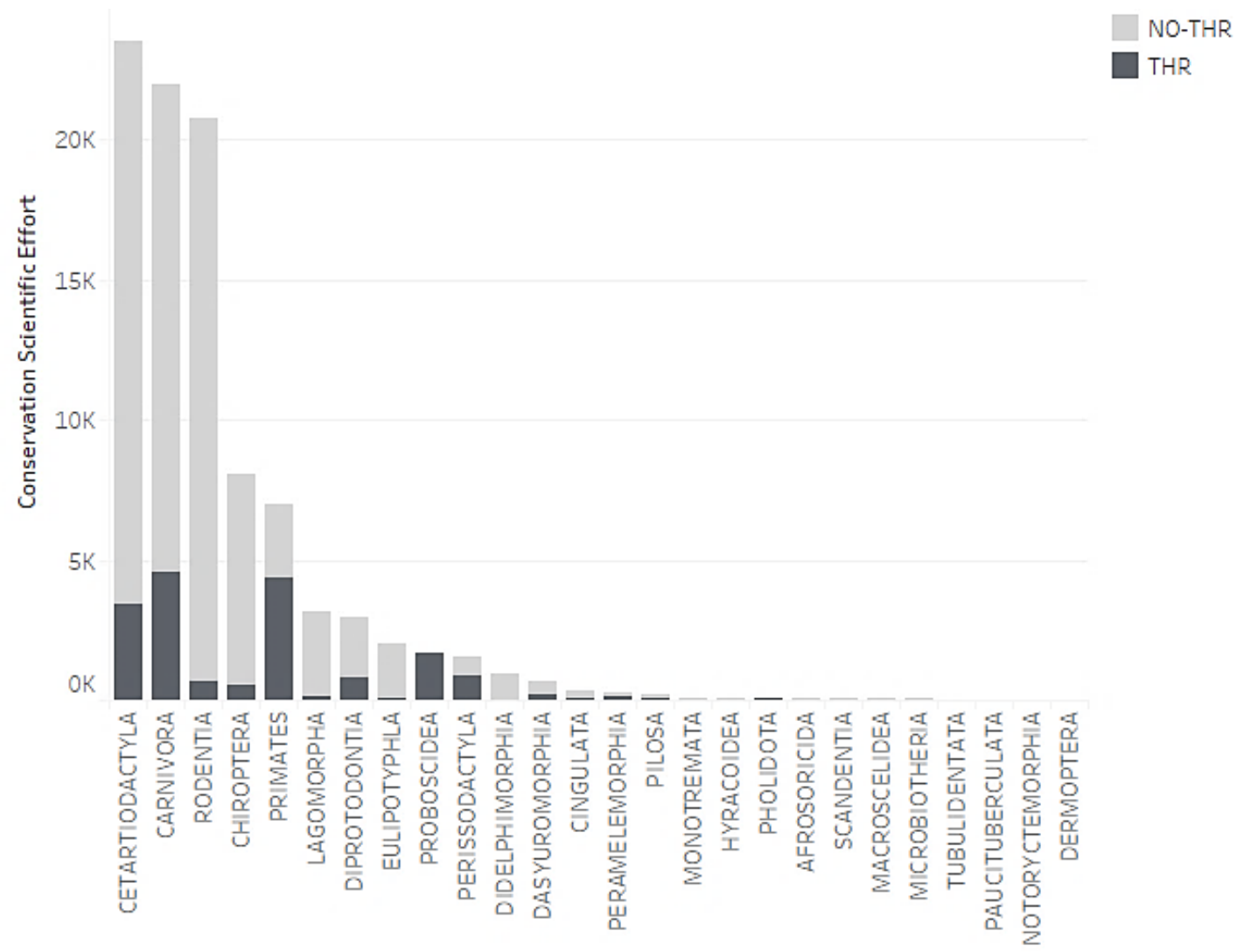


684 Table S1. Set of best models used in Hurdle Zero Model analysis. The 0-1 values in the 685 columns of the variables represent the absence and presence of the variables in the zero and 686 count models, respectively.

687

\begin{tabular}{|c|c|c|c|c|c|}
\hline $\begin{array}{c}\text { Model } \\
\text { rank }\end{array}$ & Variables in count model & Variables in hurdle model & AICc & $\triangle \mathrm{AICc}$ & wi \\
\hline 1 & $\begin{array}{l}\text { Body mass + Scientific capacity + } \\
\text { Years describing + E.D. score + } \\
\text { Geographic range }+ \text { Nocturnal + } \\
\text { Introduced species + Threatened }\end{array}$ & $\begin{array}{c}\text { Body mass }+ \text { Scientific capacity }+ \\
\text { Years describing + E.D. score }+ \\
\text { Geographic range }+ \text { Threatened }\end{array}$ & 106209.5 & 0.00 & 0.44 \\
\hline 2 & $\begin{array}{l}\text { Body mass }+ \text { Scientific capacity }+ \\
\text { Years describing }+ \text { E.D. score }+ \\
\text { Geographic range }+ \text { Nocturnal }+ \\
\text { Introduced species }+ \text { Threatened }\end{array}$ & $\begin{array}{c}\text { Body mass + Scientific capacity + } \\
\text { Years describing + Geographic } \\
\text { range }+ \text { Threatened }\end{array}$ & 106211.3 & 1.74 & 0.18 \\
\hline 3 & $\begin{array}{l}\text { Body mass + Scientific capacity + } \\
\text { Years describing + E.D. score }+ \\
\text { Geographic range }+ \text { Nocturnal }+ \\
\text { Introduced species }+ \text { Threatened }\end{array}$ & $\begin{array}{c}\text { Body mass }+ \text { Scientific capacity }+ \\
\text { Years describing + E.D. score }+ \\
\text { Geographic range }+ \text { Nocturnal }+ \\
\text { Threatened }\end{array}$ & 106211.4 & 1.91 & 0.17 \\
\hline 4 & $\begin{array}{l}\text { Body mass }+ \text { Scientific capacity }+ \\
\text { Years describing }+ \text { E.D. score }+ \\
\text { Geographic range }+ \text { Nocturnal }+ \\
\text { Introduced species }+ \text { Threatened }\end{array}$ & $\begin{array}{c}\text { Body mass + Scientific capacity + } \\
\text { Years describing + E.D. score + } \\
\text { Geographic range }\end{array}$ & 106211.8 & 2.31 & 0.14 \\
\hline 5 & $\begin{array}{c}\text { Body mass + Scientific capacity + } \\
\text { Years describing + E.D. score + } \\
\text { Geographic range + Nocturnal + } \\
\text { Introduced species + Threatened }\end{array}$ & $\begin{array}{c}\text { Body mass + Scientific capacity + } \\
\text { Years describing + Geographic } \\
\text { range + Nocturnal + Threatened }\end{array}$ & 106213.1 & 3.56 & 0.07 \\
\hline
\end{tabular}

